\title{
The Epidemiological Features of Amputations at the University Teaching Hospital in Lusaka, Zambia
}

\author{
Deliwe Mangowela, Esther Munalula-Nkandu, Kangwa M. Chileshe, Hastings Shula, \\ Loveness A. Nkhata*
}

University of Zambia, Department of Physiotherapy, School of Medicine, Lusaka, Zambia

Email address:

Lnkhata@yahoo.com (L. A. Nkhata)

\section{To cite this article:}

Deliwe Mangowela, Esther Munalula-Nkandu, Kangwa M. Chileshe, Hastings Shula, Loveness A. Nkhata. The Epidemiological Features of Amputations at the University Teaching Hospital in Lusaka, Zambia. Science Journal of Public Health. Vol. 3, No. 6, 2015 , pp. 825-829. doi: $10.11648 /$ j.sjph.20150306.15

\begin{abstract}
Introduction: While major limb amputations are reported to be a major surgical procedure that is a preventable public health problem, they are associated with profound economic, social and psychological effects on the patient, family and the country at large. There is however, limited data on the epidemiological features of amputations in developing countries where the impact is huge due to poor prosthetic services and unaffordable costs where services are available. The aim of the study was to determine the epidemiological features of amputations done at the University Teaching Hospital in Lusaka, Zambia. Methods: Data was collected using a checklist. The study was retrospective and descriptive in nature. Convenient sampling was used on records of patients who underwent major limb amputations between 2013 and 2014. Results: Out of 84 records that were reviewed, the commonest indication for amputation was trauma 29.8\% ( $\mathrm{n}=25$ ), followed by Diabetic complications $21.4 \%(n=18)$ and the prevalent age group was $31-50$ years $35.8 \%(n=30)$. Men were the most affected $(70.2 \%$; $n=59)$ giving a ratio of $2.3: 1$. Lower limbs were more frequent $75 \%(n=63)$ than upper limbs $25 \%(n=21)$ ratio $3: 1$. Above knee amputation was the commonest procedure accounting for $45.2 \%(n=38)$ cases. Conclusion: Trauma and diabetes were the common indications for amputations at the University Teaching Hospital in Lusaka, Zambia and mostly affected is the productive age group of 31-50 years. Given that both are non-communicable conditions we can conclude that the majority of the amputations could have been prevented with the behaviour change and adherence to traffic regulations by drivers, more road safety education for road users, health education, early presentation and intervention on patients plus appropriate management of the common indications.
\end{abstract}

Keywords: Amputations, Epidemiological, Indications, Features, Limbs, Trauma, Diabetes, Zambia

\section{Introduction}

Limb amputation is one of the most ancient of all surgical procedures with a history of more than 2500 years dating back to the time of Hippocrates [1]. Amputations are usually the result of complications of diabetes, peripheral arterial disease (PAD), trauma, and malignant tumours often complicated by infection [2]. The leading cause of amputation has changed in the recent past given the increase in non-communicable diseases (NCDs). While major limb amputation are reported to be a major surgical procedure that is a preventable public health problem, it is associated with profound economic, social and psychological effects on the patient and family. This is more so in developing countries where the prosthetic services and accessibility to some social services facilities are limited.
The International Diabetic Association [3] has reported that some studies done in Africa have shown that trauma and diabetes are leading causes of amputations. In a study done in Nigeria, outcomes revealed that diabetes related complications were the leading cause of non-traumatic limb amputations followed by complications of traditional bone setting. Males were reported to have been more affected than women [4]. Omoke at el [5] in their study also done in Nigeria, reported that over $50 \%$ of amputations were as a results of trauma. This is similar to outcomes of a study conducted in Tanzania [6] were diabetic related complications were a second leading factor to amputations and again, more males were affected than women were. Similar outcomes have been reported in a study done in Zambia [7] where there has been a rapid increase in NCDs, which include mental health, diabetes, cardio- 
vesicular diseases, road traffic crashes and violence [8-11]. In relation to diabetes, some authors [12-14] have reported that Sub Saharan Africa is experiencing a rapid increase in type 2 diabetes mellitus. Ojuka \& Goyaram [12] have stated that the increase is from less than $1 \%$ in 1960 to $4.3 \%$ in 2012 and currently estimated at $6.4 \%$. Mbanya et al [14] have cautioned that Africa Region is expected to see the greatest increase in diabetes from 19.8 million people in 2013 to 41.4 million in 2035 should the current trends persist. In Zambia there has been an increase in the prevalence rate for diabetes, cited to have been at $3.1 \%$ in 2010 [3] with another 266,900 persons diagnosed with diabetes in 2014 as reported by the International Diabetes Foundation [15]. This study therefore set out to determine the common epidemiological features of patients who had major limb amputations at the University Teaching Hospital (UTH) in Lusaka, Zambia between January 2013 and December 2014.

\section{Methods}

This was a retrospective cross-sectional study design conducted at the UTH. Ethical approval was obtained from the University of Zambia, School of Medicine Undergraduate Research Ethics Committee (UNZASOMUREC). We conveniently sampled records of patients who underwent major limb amputation during the stated 24-month period. These were defined as amputations that involved arms and legs except amputations below the wrist and the ankle joints. A data capture sheet, which comprised a demographic component and details of the amputation, was used to collect study information and descriptive analysis of the data for trends was done using SPSS version 20 for windows.

\section{Results}

\subsection{Demographic Descriptions}

A total of 84 patient records were included in the study using the recommended criteria. From the records, the age range of patients was between 8 months to 98 years. Most patients $36 \%(\mathrm{n}=30)$ were aged between $31-50$ years and only $6 \%(\mathrm{n}=5)$ were between $11-20$ years (Figure 1). Majority $70 \%$ (59) were males giving a male to female ratio of 2.3:1 (Figure 2). Sixty-two percent $(n=52)$ were direct admissions into UTH from Lusaka and the rest were referred from other provinces. Records also showed that $38 \%(n=32)$ of these patients were married and only $8.3 \%(n=7)$ were unemployed.

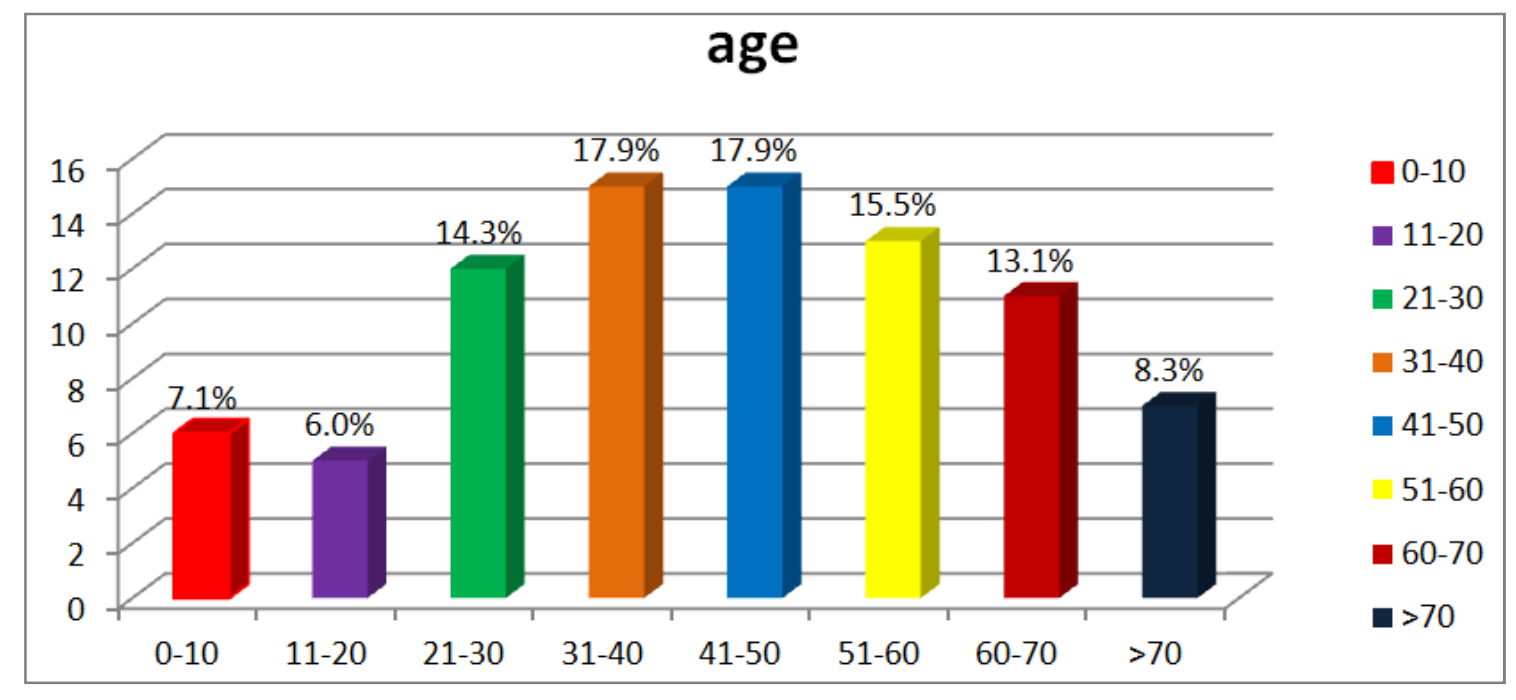

Figure 1. Age distribution.

\subsection{Common Indications for Amputations}

Figure 3 shows that trauma 29.8\% $(n=25)$ was the most common indication for amputations followed by diabetes related complications 21.4\% $(\mathrm{n}=18)$ and gangrene $19 \%$ $(n=16)$.

\subsection{Levels of Amputations}

The most frequent amputations were those of the lower limb $75 \% \quad(n=63)$. Figure 4 highlights that above knee amputation (AKA) 45.6\% ( $=38$ ) was highest followed by below knee amputation (BKA) $23.8 \%(n=23.8 \%)$ giving a ratio of $2: 1$. There was no record of bilateral limb amputations.

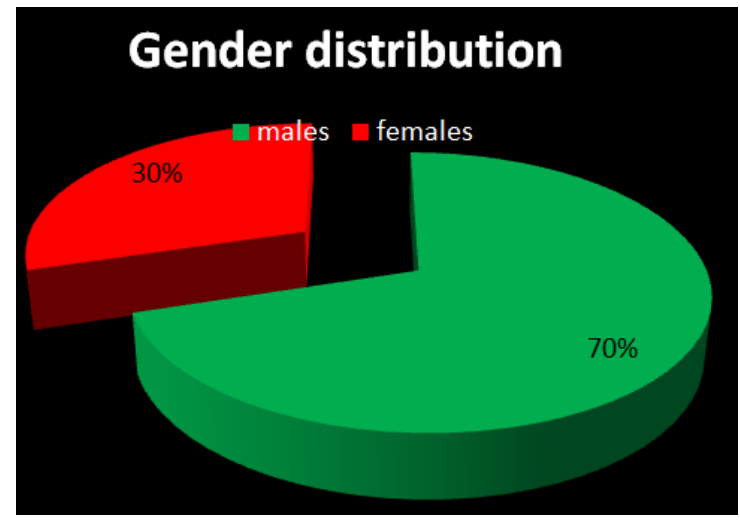

Figure 2. Gender distribution. 


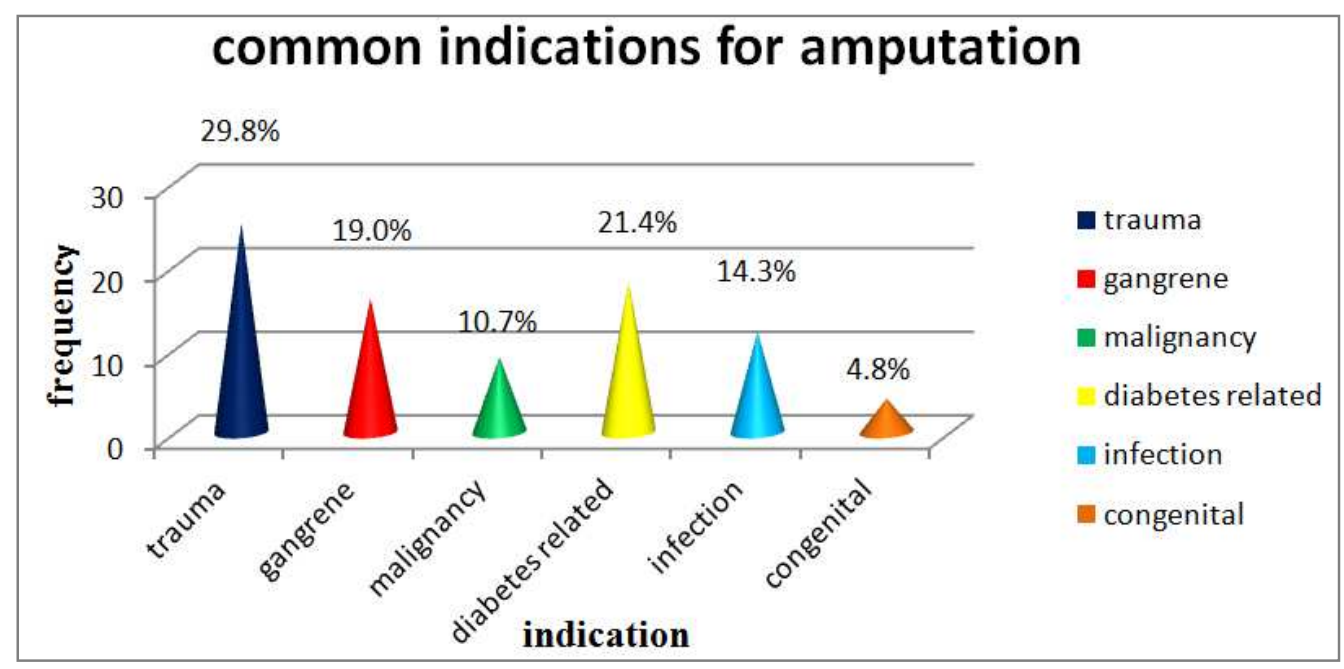

Figure 3. Common indication for amputation.

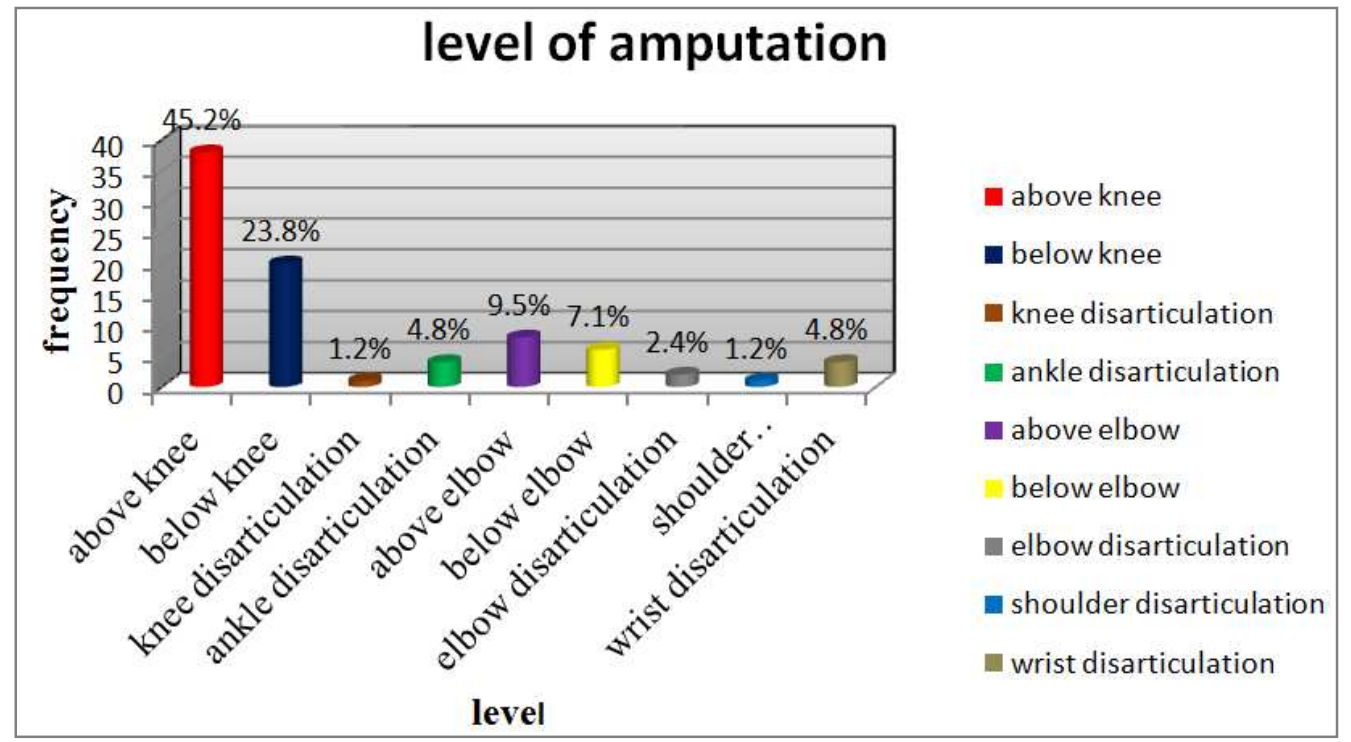

Figure 4. Level of amputation.

\subsection{Distribution for Age in Relation to the Indications for Amputation}

In patients, aged 20-40 years trauma and malignancy were most common indications for amputations whereas complications of diabetes and dry gangrene were the main indications in patients aged 40 to 60 years. Table 1 also shows that congenital limb deformities were the most common indications for amputation in children aged 10 years and below.

Table 1. Age in relation to indication

\begin{tabular}{|c|c|c|c|c|c|c|c|c|}
\hline \multirow{2}{*}{ Count } & & \multicolumn{6}{|c|}{ Indication } & \multirow{2}{*}{ Total } \\
\hline & & trauma & gangrene & cancer & diabetes related & infection & Congenital & \\
\hline \multirow{7}{*}{ Age } & $0-10$ & 1 & 0 & 1 & 0 & 0 & 4 & 6 \\
\hline & $11-20$ & 2 & 1 & 2 & 0 & 0 & 0 & 5 \\
\hline & $21-30$ & 8 & 2 & 0 & 0 & 2 & 0 & 12 \\
\hline & $31-40$ & 7 & 2 & 4 & 2 & 0 & 0 & 15 \\
\hline & $41-50$ & 3 & 3 & 1 & 5 & 3 & 0 & 15 \\
\hline & $61-70$ & 1 & 3 & 0 & 4 & 3 & 0 & 11 \\
\hline & 71 and above & 0 & 2 & 0 & 3 & 2 & 0 & 7 \\
\hline Total & & 25 & 16 & 9 & 18 & 12 & 4 & 84 \\
\hline
\end{tabular}


Table 2. Limbs amputated in relation to the indication.

\begin{tabular}{|c|c|c|c|c|c|c|c|c|}
\hline \multirow{2}{*}{ Count } & & \multicolumn{6}{|c|}{ Indication } & \multirow{2}{*}{ Total } \\
\hline & & Trauma & gangrene & cancer & diabetes related & Infection & congenital & \\
\hline \multirow{2}{*}{$\begin{array}{l}\text { Limb } \\
\text { amputated } \\
\text { Total }\end{array}$} & upper limb & 9 & 2 & 5 & 1 & 3 & 1 & 21 \\
\hline & & 25 & 16 & 9 & 18 & 12 & 4 & 84 \\
\hline
\end{tabular}

\subsection{Distribution for Limbs Amputated in Relation to the Indications}

In table 2 trauma $42.9 \%(n=9)$ and malignancy $23.8 \%(n=5)$ were the most common indications for upper limb amputations while diabetes related complications $27 \%(n=17)$ and trauma $25.4 \%(n=16)$ were the most common indications for lower limb amputations.

\section{Discussion}

The records for this study highlight that most patients that underwent major limb amputations were aged between 31-50 years, which is similar to other studies done elsewhere [1617]. Other studies [18-19] have reported even a lower peak age incident than that of our study. For Zambia, the peak age represents the productive age group whose contribution to the economy would be optimum without the physical and psychosocial disability that accompanies amputation, particularly in a developing country like Zambia. This is more so, given the infrastructure and social sector limitations that increase the challenges of disability and handicap for some of these patients.

In this study, trauma was a major contributor to amputations and males were predominately affected, an outcome that is similar to the findings from others studies [6, 20]. In most developing countries, there is more likelihood for males to take professions like being a truck driver, bus driver or working in the mines. Persons in these professions are more likely to be involved in trauma especially road crashes. This would possibly explain why more males in our study had amputations resulting from trauma.

Evaluation on road crashes in developing countries [11] has shown a high incidence of road crashes and injuries among pedestrians who frequently use heavily populated roads. This is often compounded by the fact that there are no reserved walkways for pedestrians. Country specific reports for Zambia have also reported the same [8-11]. In our study, records showed that majority of patients were unemployed. Although, the variable did not contribute significantly towards predisposition to amputation it is assumed that most patients were road users such as pedestrians and may have been involved in one way or another in road crashes that led to these amputations.

As reported in other studies [21-23] trauma was the most common indication for amputation in this study. However, this outcome is also different from studies that reported diabetes related complications as the leading cause of amputations $[4,6]$. This again underlines the fact that NCDs are contributing significantly towards amputations.

Above knee amputation (AKA) was the most common procedure performed seconded by below knee amputations (BKA), this is similar to what was reported by Tembo [22] and Chalya [6] whose studies affirm that AKA is a commonly performed procedure. However, in an earlier study BKA was reported as the most common procedure performed [23]. In relation to the upper limbs, above elbow amputations are reported to be common $[17,21]$. Our study shows that most amputations were that of the lower limbs. This finding confirms the earlier findings that lower extremities are injured more often than the upper extremities and that diabetic gangrene is common on the lower extremities than elsewhere on the body $[6,17,18]$.

This study was limited to a two-year review. More years could have given a better presentation of the situation given the high number of diabetes and trauma related injuries. As a retrospective study there were challenges retrieving patients' data. We recommend the need for an additional electronic storage of patients' files. Health practitioners also need to pay particular attention to public health education concerning predisposing factors in order to reduce on complications of diabetes. Further, all stakeholders also need to pay close attention to predisposing factors related to road crashes and adhere to road safety regulations.

\section{Conclusion}

The most common indications for major limb amputations done at UTH were trauma and diabetes related complications. Given that, both are non-communicable conditions, we can conclude that the majority of the amputations could have been prevented with the behaviour change of drivers, more road safety education by road users, health education, early presentation and intervention on patients plus appropriate management of the common indications. Additionally, a change in life style behaviour that predisposes to traumatic injuries such as driving while under the influence of intoxicating substances such as alcohol needs to continuously receive stringent attention by road users and regulators.

\section{Acknowledgements}

This work arose from a dissertation that was submitted to the University of Zambia (UNZA) in partial fulfillment for the award of a Bachelor of Science Degree in Physiotherapy in the Department of Physiotherapy of the School of Medicine. We thank management of the University Teaching Hospital and members of the Department of Physiotherapy of UNZA for their valuable contributions. 


\section{References}

[1] Paudel B, Shrestha BK, Banskota AK (2005). Two faces of major lower limb amputations. Kathmandu University Medical Journal, 3(11):212-216.

[2] Ephraim PL, Dillingham TR, Sector M, Pezzin LE, Mac Kenzie EJ (2003). Epidemiology of limb loss and congenital limb deficiency: A review of the literature. Arch. Phys. Med. Rehabilitation, 84:747-761.

[3] International Diabetes Federation (2010). Diabetes Prevalence-Country Rankings. http://www.allcountries.org/ranks/diabetes_prevalence_countr y_ranks.html Accessed $31^{\text {st }}$ July 2015.

[4] Kaka B, Ogwunyike. O, Idowu. O, Olagoke J (2012). Epidemiologic features of amputation in Kano Nigeria in WCPT 2014 conference programme and abstract p; 66.

[5] Omoke NI, Chukwu CO, Madubueze CC, Oyakhiolme OP (2012). Outcome of road traffic injuries received in the emergency room of a teaching hospital, Southeast Nigeria. Tropical Doctor, 42(1):18-22. doi:10.1258/td.2011.110030.

[6] Chalya L, Mabula B, Dass M (2012). Major Limb Amputations At a tertiary Hospital in Tanzania. Journal of Orthopaedic Surgery and Research, 7:18 http://www.josronline.com/content/14/12/18 Accessed $31^{\text {st }}$ July 2015.

[7] Lungu S (2006) The Pattern of Lower Limb Amputations in Zambia: Medical Journal of Zambia, article 17. http://www.mjz.co.zm/article/72-pattern-lower-limbamputations-zambia on 11.12.14 Accessed on $31^{\text {st }}$ July 2015.

[8] CSO, MoH, TDRC, UNZA (2009). Zambia Demographic Health Survey, 2006-2007.

[9] GRZ Ministry of Health (2011). National Health Strategy 2011- 2015.

[10] Simoonga M (2009) Road Safety in Lusaka City and Community Approaches to Road Safety. Lusaka City Council. http://www.gtkp.com/userfiles/LCC20road20safety20in20Lus aka20city.pdf Accessed: 31 ${ }^{\text {st }}$ July, 2015.

[11] WHO (2013) Road safety in WHO Africa Region. The Facts 2013.http://www.who.int/violence_injury_prevention/road_saf ety_status/2013/report/factsheetafro.pdf?ua $=1$ Accessed $31^{\text {st }}$ July 2015.

[12] Ojuka EO, Goyaram V (2014). Increasing prevalence of type 2 diabetes in Sub-Saharan Africa: Not only a case of inadequate physical activity. Medicine \& Sport Science, 60: 27-35. doi: 10.1159/000357333.
[13] Azandjeme CS, Bouchard M, Fayomi B, Djrolo F, Houinato D, Delisle H (2013). Growing burden of diabetes in Sub-Saharan Africa: Contribution of pesticides? Current Diabetes Review, 9(6): 437-49.

[14] Mbanya JC, Assah FK, Saji J, Atanga EN (2014). Obesity \& type 2 diabetes in Sub-Saharan Africa. Current Diabetes Reports, 14(7):501. doi: 10.1007/s11892-014-0501-5.

[15] International Diabetes Foundation (2014). IDF Diabetes Atlas Sixth Edition. http://www.idf.org/diabetesatlas/downloads Accessed 31st July, 2015.

[16] Masood J, Irfan A, Ghulam M, (2008). Current Indications for Major Lower Limb Amputation. Pakistan J. Surg, 24(4):228231.

[17] Bruun C1, Siersma V, Guassora AD, Holstein P, de Fine Olivarius N (2013). Amputations and foot ulcers in patients newly diagnosed with type 2 diabetes mellitus and observed for 19 years. The role of age, gender and co-morbidity. Diabet Med. 2013 Aug; 30(8):964-72. doi: 10.1111/dme.12196.

[18] Umaru RH, Gali BM, Ali N (2004). Role of inappropriate traditional splintage in limb amputation in Maiduguri, Nigeria. Annals of African Medicine, 3(3):138-140.

[19] Hazmy W, Mahamud M, Ashikin N, Jamilah S, Yee LE, Shong HK (2001). Major limb amputations in Seremban Hospital: a review of 204 cases from 1997-1999. Med J Malaysia, Jun; 56 Suppl C: 3-7.

[20] Ajibade.A, Akinniyi.O.T, Okoye. C.S (2013). Indications and Implications of Major Limb Amputations in Nigeria. Ghana Medical Journal 47 (4): 185-188.

[21] Awori KO, Atinga JE (2007). Lower limb amputations at the Kenyatta National Hospital, Nairobi. East Afr Med J. 2007 Mar; 84(3): 121-6.

[22] Tembo P (2012). A study of indications and complications of the lower limb amputations in the University Teaching Hospital, Lusaka, Zambia. Master's Thesis, University of Zambia.

[23] Nwankwo OE, Katchy AU, (2004). Surgical limb amputation: a five year experience at Hilltop Orthopaedic Hospital Enugu, Nigeria. Nig J Orthop Trauma, 3: 139-149.

[24] Buckley CM, Ali F, Roberts GA, Kearney PM, Perry IJ, Bradley CP (2014). Timing of access to secondary healthcare services and lower extremity amputations in patients with diabetes: a case-control study. BMJ Open Diabetes Res Care. 2015 Aug 26; 3(1): e000069. doi: 10.1136/bmjdrc-2014000069. eCollection 2015. 